\title{
The theoretical investigation on influence the fuel spray geometry on the combustion and emission characteristic of the marine diesel engine
}

\begin{abstract}
The paper presents an analysis of the influence of the fuel spray geometry on the combustion and emission characteristic of the marine 4-stroke Diesel engine. Presented analysis was prepared based on computational fluid dynamic model (CFD). Initial and boundary conditions of the model as well as data used to model validation were collected during the laboratory study. Calculations were conducted for two different fuel injectors with changed nozzle holes diameters, the number of nozzle holes and the angle between holes axis. The increase of the fuel nozzle holes diameter causes the decrease of the fuel spray tip penetration, but simultaneously the decrease of holes number causes that auto-ignition delay is not changed. The increase of the angle between holes axis from $150^{\circ}$ to $158^{\circ}$ causes fuel ingintion near cylinder head wall. Result of this is the increase of CO fraction. The deterioration of fuel combustion causes the decrease of $\mathrm{NO}_{x}$ mass fraction in the cylinder also.
\end{abstract}

Key words: marine engine, CFD, combustion model, fuel injection, emission

\section{Introduction}

Commonly used sources of mechanical energy on ships are Diesel engines. The source of mentioned energy is the combustion process in engine cylinders. Products of combustion process are emitted into the atmosphere and due to large dimensions of marine engines and many weeks of continuous operation the air pollution is large. For example marine engine with nominal power of $20 \mathrm{MW}$ consumes almost 100 tons of fuel per day (on the assumption of value of specific fuel consumption of $200 \mathrm{~g} / \mathrm{kWh}$ ) and emits 300 tons of $\mathrm{CO}_{2}$. Due to the significant air pollution and high costs of marine engines operation, scientific investigations are conducted to obtain the reduction of the fuel consumption. Moreover temperature of the combustion process should be reducing due to the nitric oxides emission reduction. The combustion process in Diesel engine cylinder is mainly determined by the fuel injection process [8]. Fuel delivered by the injector is brake-up and simultaneously evaporated and mixed with air/exhaust gas mixture and combusted. According to [16] non-reacting phase of fuel propagation is divided in two stages; primary and secondary brake-up. The course and parameters of mentioned phenomena are determined e.g. by fuel injection pressure, diameters of nozzle holes, the fuel flow, pressure in the engine cylinder and properties of fuel [6]. The fuel temperature change causes the change of fuel viscosity and fuel density. According to this, colder diesel fuel had a longer liquid tip penetration length and a narrower spray angle than the warm diesel fuel. This phenomenon attributed to the poor atomization [18] and the vaporization [7]. It should be noted that in the case of heavy fuel oil presented trend is not observed [17].

In the literature we can find a lot of work concerning parameters of the fuel injection and their impact of the combustion process and the characteristic of emission. According to [2] the increase of fuel injection pressure causes the increase of $\mathrm{NO}_{\mathrm{x}}$ emission and the decrease of $\mathrm{CO}$ emission. The increase of injection pressure causes the decrease of SMD of fuel spray leads to better mixing on air and $\mathrm{CO}$ reduction. The shape of fuel nozzle holes has significant impact on the engine performance and emission characteristic [20]. The increase of fuel conicity causes the increase of the spray cone angle and the decrease of $\mathrm{NO}_{x}$ emission [21]. The key factor for the Diesel engine performance and the emission is the fuel injection timing. Early fuel injection causes the delay of the fuel ignition due to lower pressure and temperature in the engine cylinder. According to [9] the delay of fuel injection causes the increase of $\mathrm{CO}$ and $\mathrm{NO}_{\mathrm{x}}$ emission. The sharpness of the fuel nozzle holes edge is important to the fuel atomization also $[4,19]$. A method of fuel injector activation affects the parameters of fuel spray. On [26, 23] works measurement results for piezo- and solenoid driven fuel injectors were presented. The energizing of the fuel injector by piezoelectric system with fuel injection pressure equals 60MPa causes lower tip penetration and higher spray cone angle in relation to energizing by the solenoid system. It should be emphasized that available publications concerns fuel injectors and injection conditions in diesel engines with small dimensions in relation to marine engines [5]. Therefore the main target of paper is the theoretical analysis of the influence of fuel spray geometry on the combustion and the emission characteristic of the marine Diesel engine. Chosen research object is 3-cylinder, 4-stroke, supercharged and intercooled marine engine, operated at constant speed and constant power output.

\section{Experiment description}

\subsection{Laboratory test}

The study was carried out by using an AL25/30 Cegielski-Sulzer marine, installed in the Laboratory of Internal Combustion Engines, Gdynia Maritime University. The engine was loaded by a generator electrically connected to the water resistance and supercharged by the VTR 160 Brown-Boveri turbocharger. During the tests the engine was fueled with diesel oil of properties presented in Table 1 , and operated at the constant speed of $750 \mathrm{rpm}$ and constant output power of $250 \mathrm{~kW}$. Important engine parameters are given in Table 2. The fueling system of the engine consisted of a Bosch type, mechanically controlled fuel pumps connected to injectors with multi-hole nozzles. Two types of nozzles with parameters presented in Table 3 are tested. 
Close description of the laboratory test with the schematic diagram of the laboratory stand and the accuracy and ranges of measurement equipment are presented in [10].

Table 1. Fuel oil properties [10]

\begin{tabular}{|l|c|c|}
\hline Parameter & Unit & Value \\
\hline Density at $15^{\circ} \mathrm{C}$ & $\mathrm{kg} / \mathrm{m}^{3}$ & 827.3 \\
\hline Viscosity at $40^{\circ} \mathrm{C}$ & $\mathrm{mm}^{2} / \mathrm{s}$ & 2.636 \\
\hline Cetane number & - & 53.2 \\
\hline
\end{tabular}

Table 2. Laboratory engine properties [10]

\begin{tabular}{|l|c|c|}
\hline Parameter & Unit & Value \\
\hline Max. electric power & $\mathrm{kW}$ & 250 \\
\hline Rotational speed & $\mathrm{rpm}$ & 750 \\
\hline Cylinder number & - & 3 \\
\hline Cylinder bore & $\mathrm{mm}$ & 250 \\
\hline Stroke & $\mathrm{mm}$ & 300 \\
\hline Compression ratio & - & 12.7 \\
\hline Fuel nozzle opening pressure & $\mathrm{MPa}$ & 25 \\
\hline Start of fuel injection & ${ }^{\circ}$ before TDC & 18 \\
\hline
\end{tabular}

Table 3. Fuel nozzles parameters

\begin{tabular}{|l|c|c|}
\hline Fuel nozzle & Nozzle 1 & Nozzle 2 \\
\hline Number of holes & 9 & 8 \\
\hline Holes diameter [mm] & 0.325 & 0.375 \\
\hline Angle between holes axis $\left[^{\circ}\right]$ & 150 & 158 \\
\hline Conicity K factor $[22]$ & 1 & 1 \\
\hline
\end{tabular}

\subsection{CFD model description}

CFD model was prepared on the basis of the moving mesh of the engine cylinder. Mentioned mesh was prepared for overall volume of the engine cylinder and allows preparing the calculations for full crankshaft rotation. The moving mesh was prepared using "Fame Engine Plus" tool from the AVL Fire software. Quantitative characteristic of the fuel injection was calculated on the basis on measured crankshaft position of the injection start, the fuel consumption and fuel pressure measured behind the fuel injector. It should be noted that mentioned characteristic is different for both considered nozzles $[3,25]$. The WAVE fuel brakeup model with the Wakisaka modification and the Dukowicz evaporation model were used. The 3Z-ECFM model of the auto-ignition and the combustion process, based on the Euler description was chosen. The amount and the composition of the mixture in each finite volumes of the moving mesh are based on the average of Navier-Stokes equations and continuity equations. The turbulent flow was iteratively calculated by the k-zeta-f model with pressure correction by the SIMPLE model. The "upwind" differential scheme was used to energy balances and turbulent flows calculation. The central scheme of differential equations was used to calculate the flow continuity equations. The Zeldowicz's, the Fenimore as well as fuel mechanisms of $\mathrm{NO}_{\mathrm{x}}$ formation are used simultaneously. Detailed description of the model and the validation of calculation results are presented in [14]. The validation as well as the initial and the boundary conditions are collected during laboratory measurements [10]. Model was validated on the basis on measured combustion pressure in the cylinder and the $\mathrm{NO}_{\mathrm{x}}$ and the oxygen fraction in the exhaust duct.

\section{Results and discussion}

The change of nozzles, presented in Table 3, causes the change of nozzle holes diameter and the number of holes as well as the angle between holes axis. The cross section area of holes of the nozzle 1 is $18.3 \%$ lower than the nozzle 2 . According to results, presented in [12] the increase of fuel nozzle holes diameter (nozzle 2) causes the increase of the SMD in the initial stage of the injection process. The effect of this phenomenon is slowdown of the fuel evaporation and the auto-ignition. This situation promotes elongation of fuel tip penetration of not evaporated fuel but the quickness of the fuel propagation in the combustion chamber is lower. The result of this is decrease of both combustion temperature and pressure. According to [15] the decrease of the fuel nozzle holes number causes opposite changes in the intensity of the fuel evaporation and the auto-ignition in relation to the increase of the fuel nozzle holes diameter. The intensity of the combustion process increases also. The result of this is the increase of combustion temperature and $\mathrm{NO}_{\mathrm{x}}$ formation. The analysis of the influence of the changing of the angle between fuel holes axis on the combustion process is presented in [13]. According to presented results the increase of mentioned angle causes the increase of intensity of the diffusion stage of combustion and the decrease of the intensity of the kinetic stage of the combustion. Result of this is the increase of both combustion temperature and pressure. The increase of the angle causes the intense of the $\mathrm{NO}_{\mathrm{x}}$ formation also.

Presented analysis shows that changing the nozzle 1 to the nozzle 2 causes complex and in some part opposite influence of combustion and emission parameters. Fig. 1 presents measured values of fuel pressure behind fuel injector. According to presented results the change of nozzle geometry causes a little change of fuel pressure.

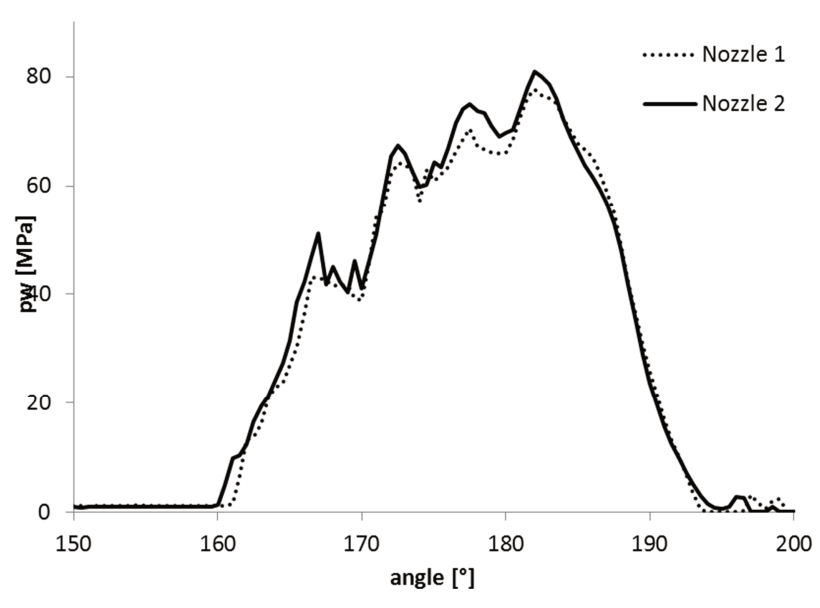

Fig. 1. Fuel pressure behind the injector

Figure 2 presents the fuel spray tip penetration, calculated for both nozzles. According to presented results the increase of the diameter and the angle between axis of nozzle holes and the decrease of the holes number causes the increase of the fuel tip penetration.

Deteriorations in the fuel tip penetration at the end of injection are the result of the fuel evaporation. It means, that presented geometrical changes in the fuel nozzle causes the 
increase of the initial fuel droplets diameter. The simultaneous decrease of the nozzles number causes, that the initial quantity of evaporated fuel not changed. This phenomenon is presented on the Fig. 3.

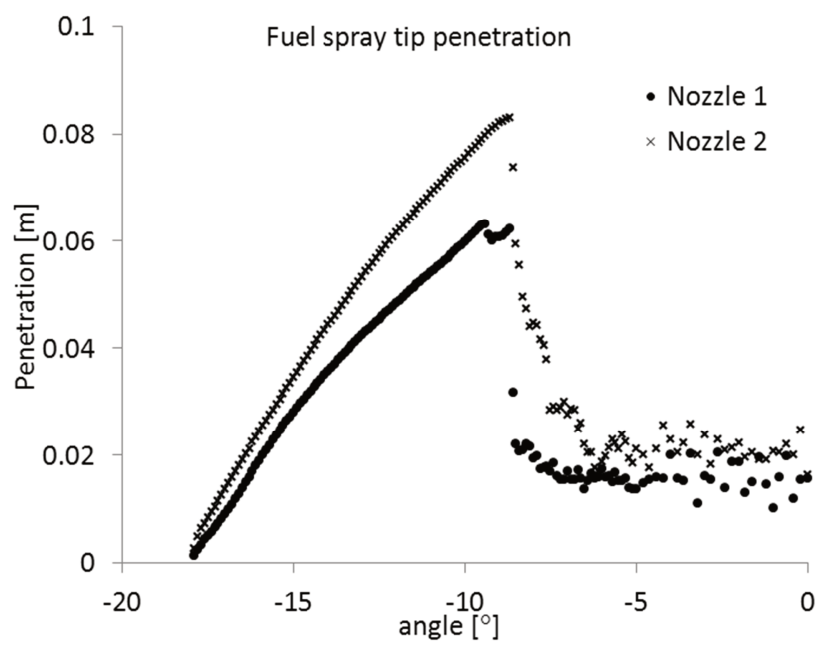

Fig. 2. Fuel tip penetration

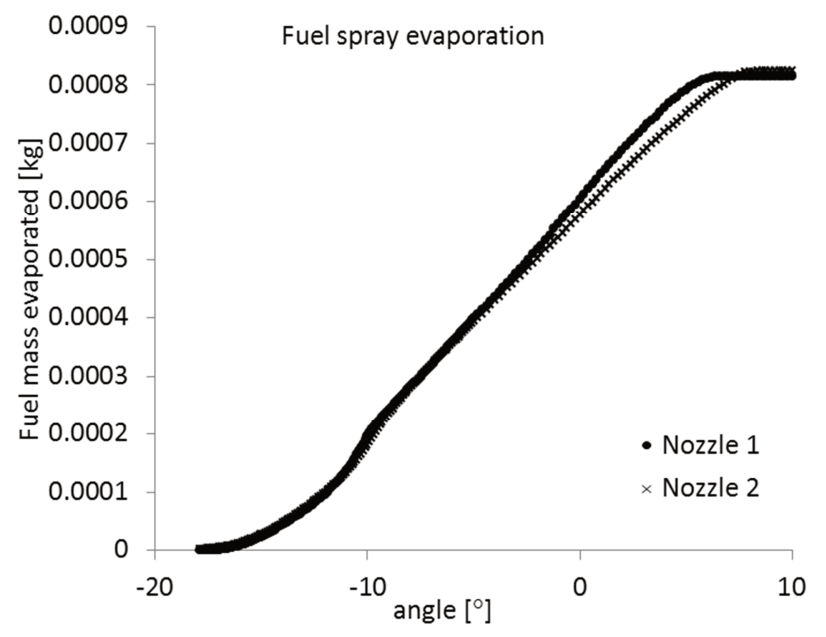

Fig. 3. Fuel spray evaporation

Use the nozzle 2 causes the delay of the fuel evaporation at the end stage of the fuel spray by $1.6^{\circ}$ of the crankshaft angle position. According to the Fig. 4, the change of the fuel nozzle geometry influences on the heat release rate. The delay of the combustion kinetic stage and the shortening of the combustion diffusion stage are observed for the nozzle 2. It should be noted, that the maximum value of the heat release in the diffusion stage is decreased and the characteristic of the heat release for this stage of combustion is narrowed. Moreover, according to presented results the auto-ignition delay not changes. This is the result of the opposite influence of the fuel nozzle holes number and the diameter on the auto-ignition delay. It should be noted, that according to [24] the increase of the angle between holes axis causes shortening the auto-ignition delay, but in mentioned citation the maximum angle not exceed $30^{\circ}$ value.

The result of heat release changes is the decrease of both combustion temperature and combustion pressure. It's interesting that according to results presented in the Fig. 5. the maximum combustion temperature decreases for the nozzle 2 , but the value of the temperature near the exhaust valve opening $\left(110^{\circ}\right.$ after TDC) increases in relation to calculation results for the nozzle 1 . The advantage of the multidimensional calculations is the possibility of the calculation and the visualization of combustion process parameters in different areas of the cylinder.

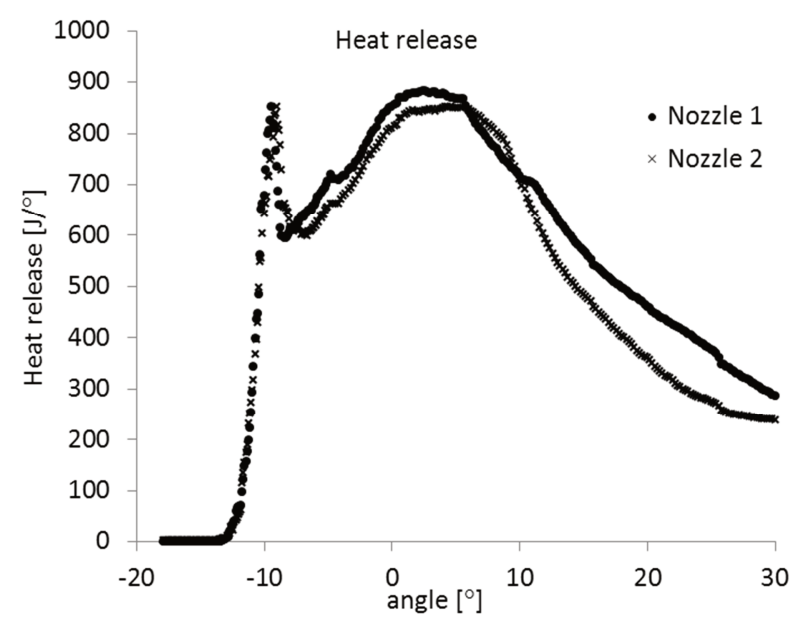

Fig. 4. Heat release rate
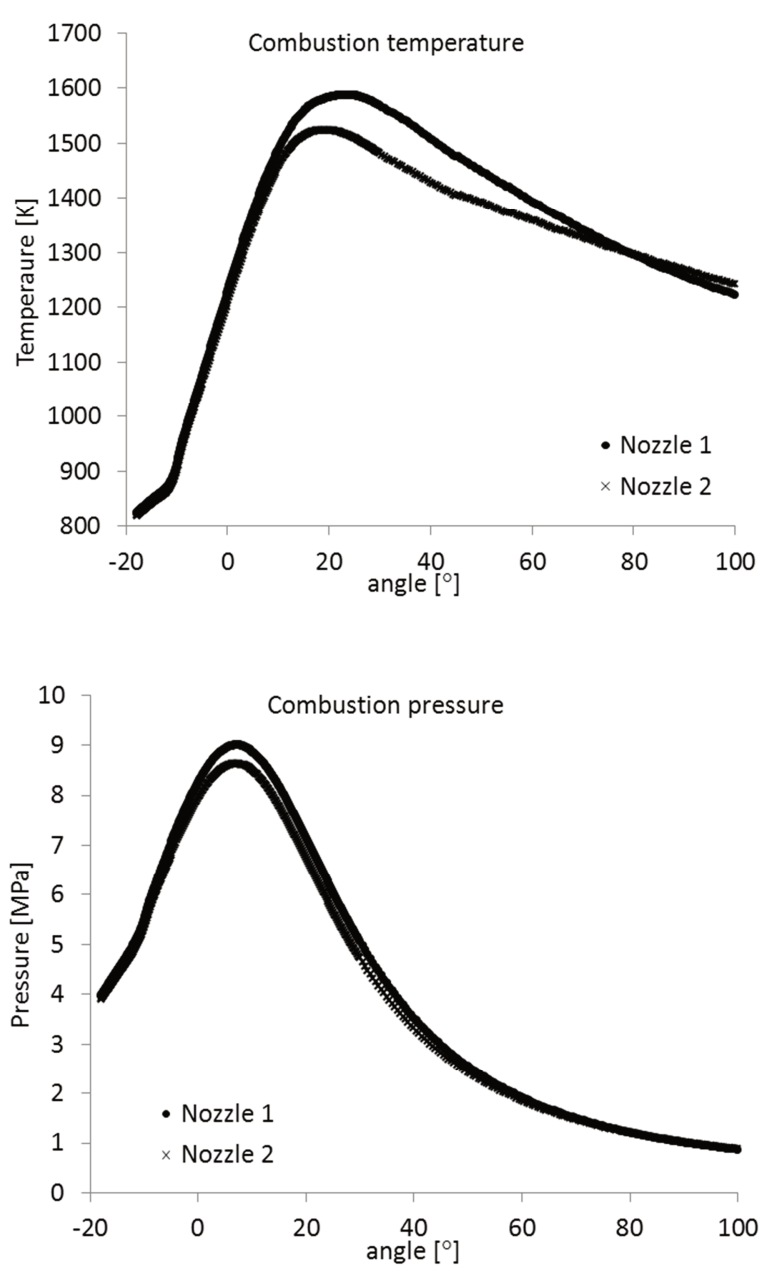

Fig. 5. Calculated temperature and pressure of combustion 


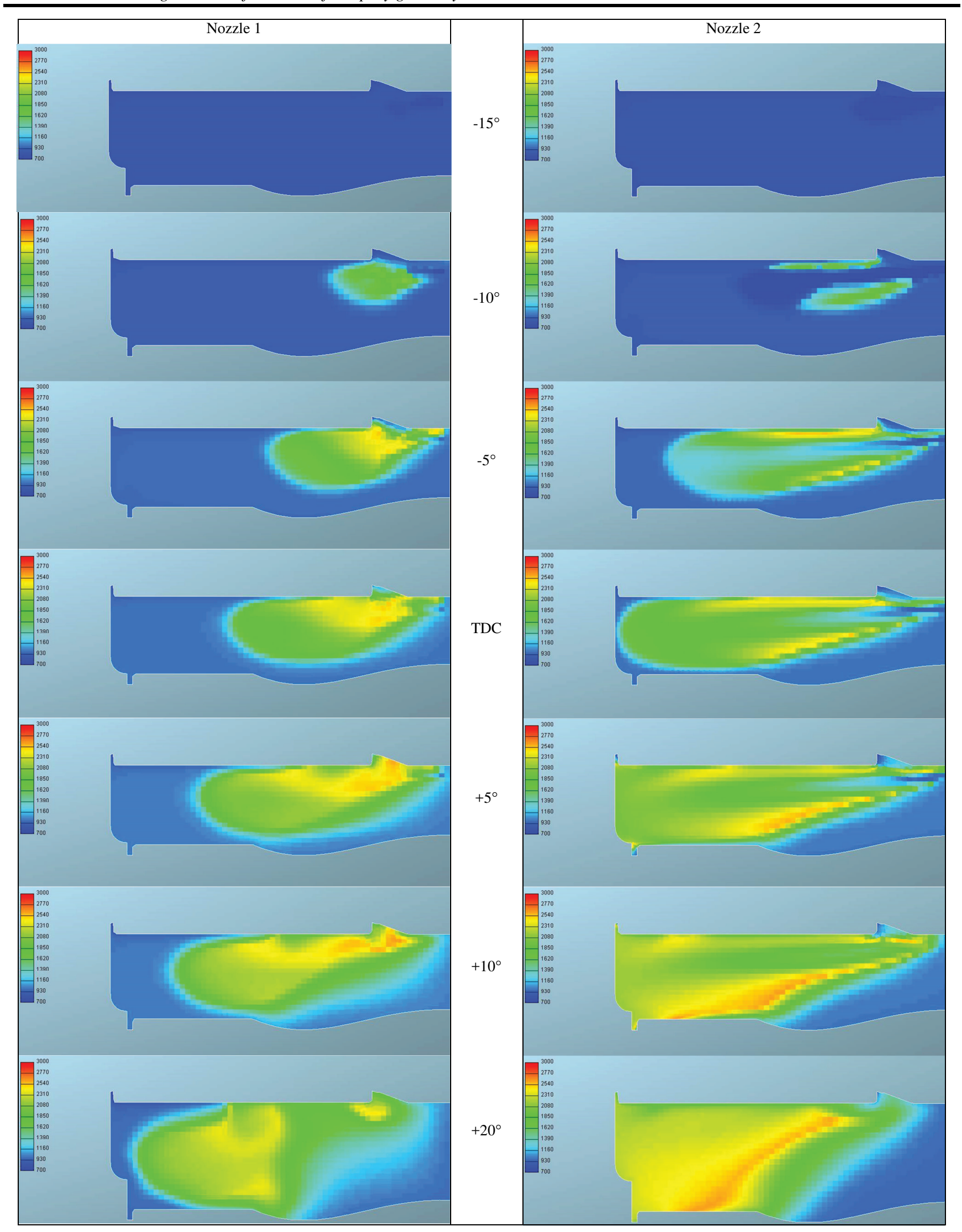

Fig. 6. Calculated temperature of combustion 


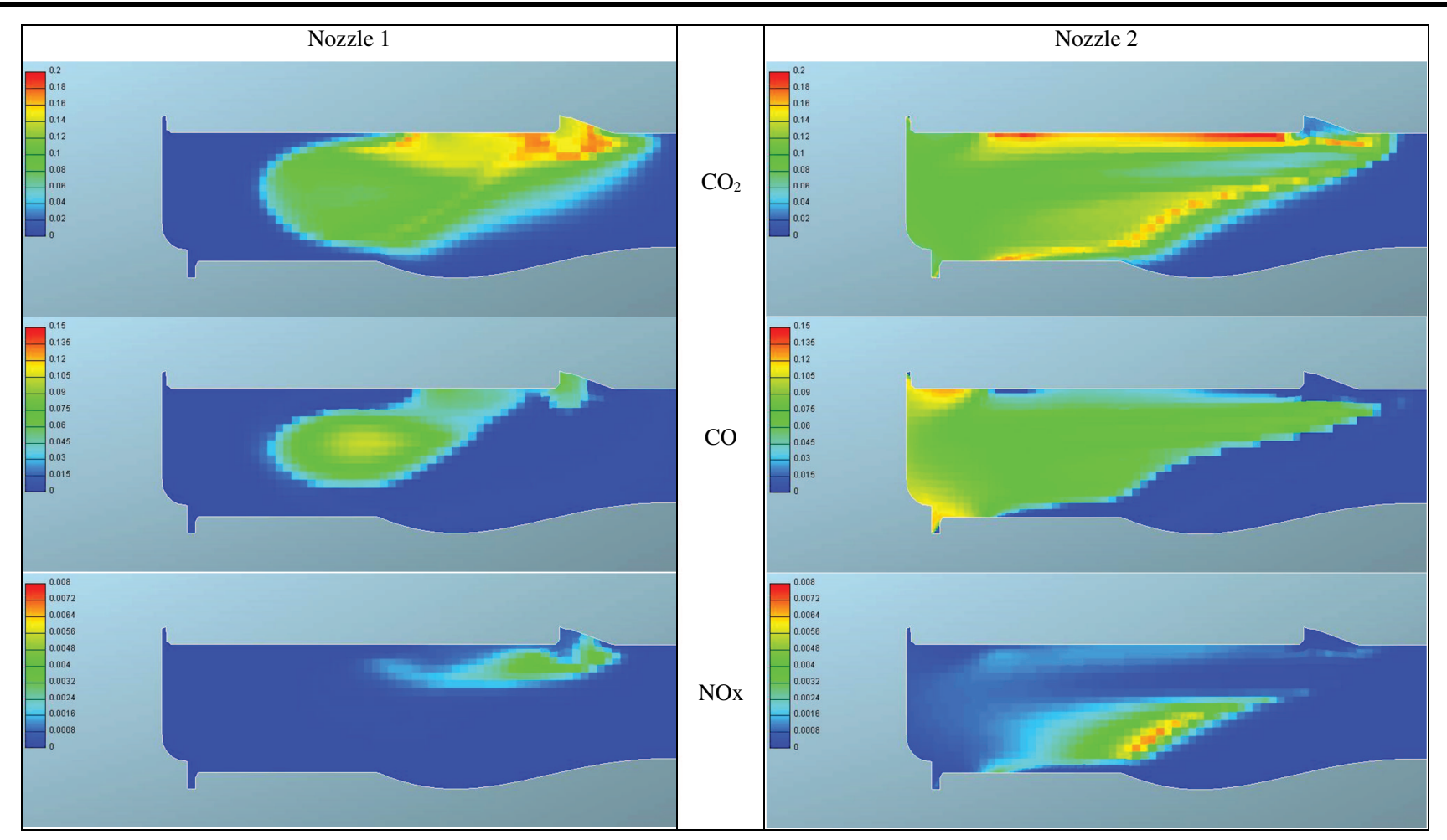

Fig. 7. Calculated fractions of chosen species for $10^{\circ}$ after TDC of crankshaft position

The Fig. 6 presents the evolution of the combustion process based on temperature in the combustion chamber for both considered nozzles. Only the left side of the cross section area is presented due to the axial symmetry of the combustion chamber. According to presented results the increase of the diameter of fuel nozzle holes causes the increase of the fuel flow. The development of fire in the combustion chamber is different for both considered nozzles. $10^{\circ}$ before TDC in the both cases the combustion process is started, but for the nozzle 1 the combustion is developed on the front of the fuel spray. The fuel injection for the nozzle 2 is more intense and the combustion is started near sides of the fuel spray. Moreover the higher temperature is observed near the wall of the cylinder head. Its result of increased the cone angle between the fuel nozzle axis from $150^{\circ}$ for the nozzle 1 to $158^{\circ}$ for the nozzle 2 . For the nozzle 2 the combustion process reaches walls of the combustion chamber at the TDC crankshaft position and in opposite to the nozzle 1 the area with not evaporated fuel is observed near nozzle holes. The combustion process for the nozzle 1 riches the cylinder walls later (at $20^{\circ}$ of the crankshaft position). The comparison of results of the temperature calculation from the Fig. 5 and the Fig. 6 for $20^{\circ}$ of the crankshaft position after TDC shows that mean temperature for the overall cylinder volume is lower for the nozzle 2 but it is possible to observe areas with higher temperatures in relation to the combustion for the nozzle 1 due to extended combustion process. The Fig. 7 presents results of the fractions calculation of chosen chemical species for $10^{\circ}$ after the TDC of crankshaft position.
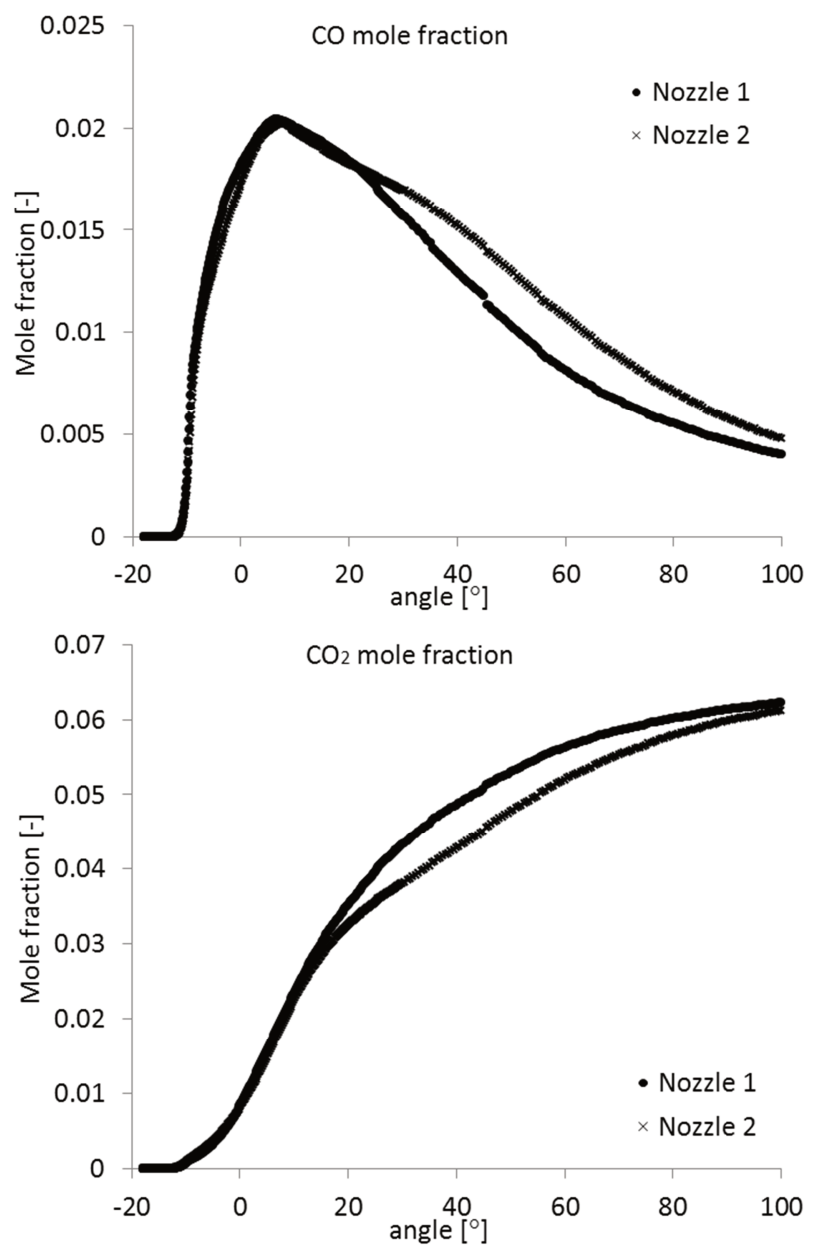

Fig. 8. $\mathrm{CO}$ and $\mathrm{CO}_{2}$ mole fractions 


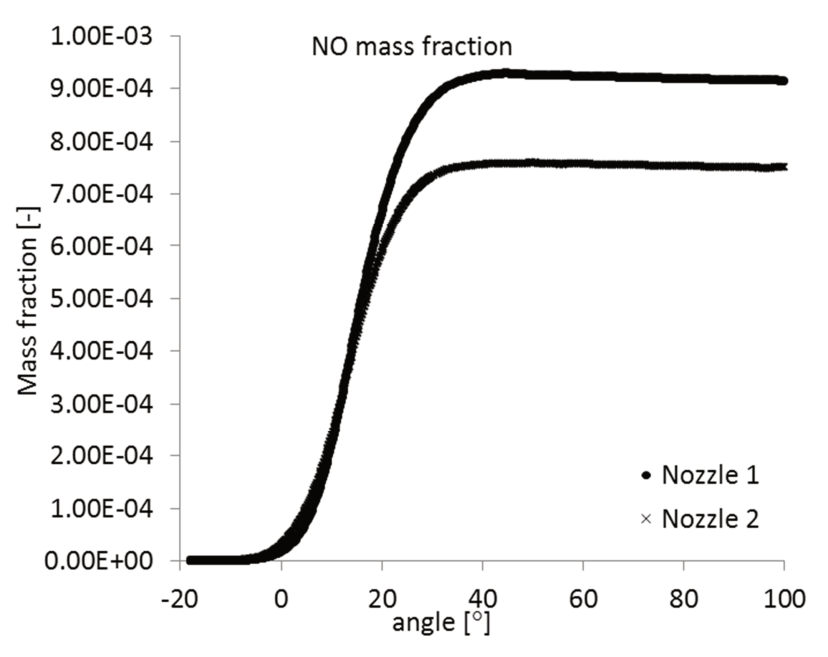

Fig. 9. $\mathrm{NO}_{\mathrm{x}}$ mass fraction

Presented results confirm the extension of the combustion process for the nozzle 2. The area of the $\mathrm{CO}$ formation is located in largest part of the cylinder volume. Comparison of results presented in the Fig. 6 and the Fig. 7 shows that the $\mathrm{NO}_{\mathrm{x}}$ formation area corresponds to areas with higher temperatures for both nozzles. According to results presented in the Fig. 7 the combustion process seems to be more homogeneous for the nozzle 2 in comparison to the nozzle 1 , but it should be noted, that results are presented for cross section through the nozzle holes axis. Changes of mean fractions of $\mathrm{CO}$ and $\mathrm{CO}_{2}$ for overall volume of cylinder are presented in the Fig. 8. The extension of the combustion process for the nozzle 2 causes the decrease of $\mathrm{CO}_{2}$ formation during the combustion. The visible combustion near cylinder walls for the nozzle 2 causes the increase of the $\mathrm{CO}$ formation also. It should be noted that fractions of both considered species are similar for both nozzles near $100^{\circ}$ after TDC (end of combustion). The Fig. 9 presents mean values of the NO mass fraction in the cylinder. The NO fraction equals $90-99 \%$ of the overall $\mathrm{NO}_{\mathrm{x}}$ fraction in internal combustion engines [1]. According to presented results the increase of the fuel holes diameter and the angle between holes axis and simultaneous the decrease of the fuel holes number causes the decrease of the NO fraction. The reason of this is the decrease of combustion pressure and temperature. This result corresponds to measurement results [11] and results from the modeling [24].

\section{Conclusions}

The theoretical investigations of the combustion and the emission characteristic of the marine 4-stroke Diesel engine are presented. Mentioned investigations are based on the 3 dimensional, milti-zone CFD model. According to presented results following conclusions may be formulated:

- The increase of the fuel nozzles holes diameter causes slowdown of the fuel vaporization and auto-ignition but simultaneous the decrease of the fuel nozzle number causes that changes in the auto-ignition delay are not observed. The slowdown of vaporization process is observed only at the end of the injection process due to the increase of the angle between nozzle holes axis.

- The increase of the fuel nozzles holes diameter causes the increase of the fuel tip penetration. The result of this is the change of fire propagation. The combustion for the nozzle 2 start near the sides of the fuel spray, and is observed near the cylinder walls, meanwhile the combustion for the nozzle 1 is started on the top of the fuel spray.

- The change of the nozzle 1 to the nozzle 2 causes the delay of the combustion kinetic stage and the shortening of the combustion diffusion stage of the combustion. The maximum value of the heat release in the diffusion stage is decreased and the characteristic of the heat release for this stage of combustion is narrowed, but the auto-ignition delay is not changed.

- The result of the fuel nozzle geometry changing is the change of pressure and temperature of the combustion. The maximum temperature in the cylinder area is observed for the nozzle 2 , but the mean value for overall cylinder volume is lower in the relation to results for the nozzle 1.

- The result of the decrease of temperature and pressure of combustion is the decrease of the $\mathrm{NO}_{\mathrm{x}}$ fraction for the combustion for the nozzle 2 .

- The CO fraction for the combustion with the nozzle 2 is lower than for the nozzle 1 . This result should be treated with the great reserve due to unsatisfactory quantitative validation with measurement values of the presented model.

\section{Acknowledgements}

The project was supported by AVL Company according to University Partnership Program and license of AVL Fire software.

\section{Nomenclature}

NOx nitric oxides

$\mathrm{CO}$ carbon oxide

SMD Sauther's Mean Diameter

$\mathrm{CO}_{2}$ carbon dioxide

TDC top dead center of crankshaft position

CFD computational Fluid Dynamic

\section{Bibliography}

[1] BENAJES, J., LÓPEZ, J.J., NOVELLA, R., REDÓN, P. Comprehensive modeling study analyzing the insights of the $\mathrm{NO}-\mathrm{NO}_{2}$ conversion process in current diesel engines. Energy Conversion and Management. 2014, 84 691-700.
[2] ÇELIKTEN, I. An experimental investigation of the effect of the injection pressure on engine performance and exhaust emission in indirect injection diesel engines. Applied Thermal Engineering. 2003, 23 (16), 2051-2060.

[3] DESANTES, J.M., GARCÍA-OLIVER, J.M., PASTOR, J.M., RAMÍREZ-HERNÁNDEZ, J.G. Influence of nozzle 
geometry on ignition and combustion for high-speed direct injection diesel engines under cold start conditions. Fuel. 2011 90(11) 3359-3368.

[4] GIMENO, J., BRACHO, G., MARTÍ-ALDARAVÍ, P., PERAZA, J.E. Experimental study of the injection conditions influence over n-dodecane and diesel sprays with two ECN single-hole nozzles. Part I: Inert atmosphere. Energy Conversion and Management. 2016, 126, 1146-1156.

[5] HEYWOOD, J. B., SHER, E. The two-stroke cycle engine. its development, operation, and design. Taylor\&Francis N.Y. 1999.

[6] HOSEINI, S.S., NAJAFI, G., GHOBADIANA, B. et al. The effect of combustion management on diesel engine emissions fueled with biodiesel-diesel blends. Renewable and Sustainable Energy Reviews. 2017, 73, 307-331.

[7] KAPUSTA, Ł.J., PIELECHA, I., WISŁOCKI, K., TEODORCZYK, A. Autoignition and combustion of n-hexane spray in subcritical and supercritical environments. $J$ Therm Anal Calorim. 2016, 123(1), 819-828.

[8] KIM, H.J., PARK, S.H., LEE, C.S. Impact of fuel spray angles and injection timing on the combustion and emission characteristics of a high-speed diesel engine. Energy. 2016, 107, 572-579.

[9] KIPLIMO, R., TOMITA, E., KAWAHARA, N., YOKOBE, S. Effects of spray impingement, injection parameters, and EGR on the combustion and emission characteristics of a PCCI diesel engine. Appl Therm Eng. 2012, 37, 165-75.

[10] KOWALSKI, J. An experimental study of emission and combustion characteristics of marine diesel engine with fuel pump malfunctions. Applied Thermal Engineering. 2014, 65, 469-476.

[11] KOWALSKI, J. An experimental study of emission and combustion Characteristics of marine diesel engine with fuel Injector malfunctions. Polish Maritime Research. 2016, 23(1), 77-84.

[12] KOWALSKI, J. Influence of fuel injector holes diameter on parameters of combustion process in the cylinder of the marine 4-stroke diesel engine. Journal of Polish CIMEEAC. 2016, 11(1), 95-102.

[13] KOWALSKI, J. The analysis of influence of fuel spray angle on $\mathrm{NO}_{\mathrm{x}}$ fraction in the exhaust gas from marine 4stroke diesel engine. Journal of Kones. 2015, 22(3), 309316.

[14] KOWALSKI, J. The model of combustion process in the marine 4-stroke engine for exhaust gas composition assessment. Combustion Engines. 2016, 165(2), 60-69.
[15] KOWALSKI, J. Wykorzystanie składu spalin w diagnostyce czterosuwowych silników okrętowych. Wydawnictwo Naukowe Instytutu Technologii Eksploatacji. Radom 2015.

[16] NAGASAKA, K., TAKAGI, T., KOYANAGI, K. YAMAUCHI, T. The development of "ne atomization injector Kenzo. JSAE Review. 2000, 21, 309-313.

[17] PARK, J., JANG, J.H., PARK, S. Effect of fuel temperature on heavy fuel oil spray characteristics in a common-rail fuel injection system for marine engines. Ocean Eng. 2015, 104, 580-589.

[18] PARK, Y., HWANG, J., BAE, C. et al. Effects of diesel fuel temperature on fuel flow and spray characteristics. Fuel. 2015, 162, 1-7.

[19] PAYRI, R., SALVADOR, F.J., GIMENO, J., PERAZA, J.E. Experimental study of the injection conditions influence over n-dodecane and diesel sprays with two ECN singlehole nozzles. Part II: Reactive atmosphere. Energy Conversion and Management. 2016, 126, 1157-1167.

[20] PAYRI, R., TORMOS, B., SALVADOR, F.J., ARANEO L. Spray droplet velocity characterization for convergent nozzles with three different diameters. Fuel. 2008, 87, 15-16.

[21] SOM, S., RAMIREZ, A.I., LONGMAN, D.E., AGGARWAL, S.K. Effect of nozzle orifice geometry on spray, combustion, and emission characteristics under diesel engine conditions. Fuel. 2011, 90, 1267-1276.

[22] SOM, S., RAMIREZ, A.I., LONGMAN, D.E., AGGARWAL, S.K. Effect of nozzle orifice geometry on spray, combustion, and emission characteristics under diesel engine conditions. Fuel. 2011, 90(3), 1267-1276.

[23] SUH, H.K., PARK, S.W., LEE, C.S. Effect of piezo-driven injection system on the macroscopic and microscopic atomization characteristics of diesel fuel spray. Fuel. 2007, 86, 2833-2845.

[24] TAGHAVIFAR, H., KHALILARYA, S., JAFARMADAR, S., BAGHERY, F. 3-D numerical consideration of nozzle structure on combustion and emission characteristics of DI diesel injector. Applied Mathematical Modelling. 2016, 40(19-20), 8630-8646.

[25] WU, X., DENG, J., CUI, H. et al. Numerical simulation of injection rate of each nozzle hole of multi-hole diesel injector. Applied Thermal Engineering. 2016, 108(5), 793-797.

[26] YU, W., YANG, W., MOHAN, B. et al. Macroscopic spray characteristics of wide distillation fuel (WDF). Appl. Energy. 2017, 185, 1372-1382.

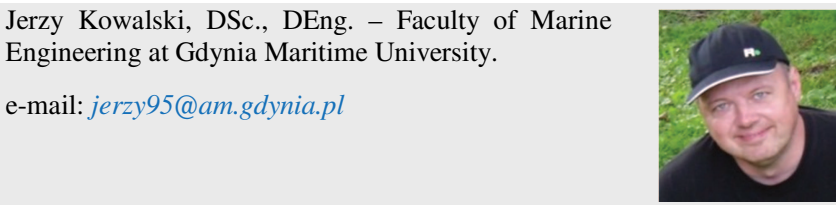

